\title{
The effect of the glucosylceramide synthase inhibitor lucerastat on cardiac repolarization: results from a thorough QT study in healthy subjects
}

\author{
Markus S. Mueller ${ }^{*}$ (D) Patricia N. Sidharta ${ }^{1}$, Christine Voors-Pette ${ }^{2}$, Borje Darpo ${ }^{3}$, Hongqi Xue $^{3}$ \\ and Jasper Dingemanse ${ }^{1}$
}

\begin{abstract}
Background: Fabry disease is a rare inherited glycosphingolipid storage disorder caused by deleterious mutations in the GLA gene coding for the lysosomal enzyme a-galactosidase A. The glucosylceramide synthase inhibitor lucerastat is an iminosugar with potential to provide oral substrate reduction therapy in Fabry disease, regardless of the patient's underlying mutation. Since lucerastat exhibits systemic exposure and many patients with Fabry disease suffer from rhythm and conduction abnormalities its effects on cardiac repolarization were evaluated in a thorough QT study.

Methods: In Part A of this randomized, double-blind, placebo-controlled phase 1 study, single oral doses of 2000 and $4000 \mathrm{mg}$ lucerastat were investigated to determine the supratherapeutic dose for Part B. The latter was a four-way crossover study to demonstrate that lucerastat at single oral therapeutic and supratherapeutic doses had no effect on the QTc interval > 10 ms using concentration-QTc modeling as primary analysis. The primary ECG endpoint was placebo-corrected change-from-baseline $(\Delta \Delta)$ in Fridericia-corrected QTc ( $\triangle \Delta$ QTcF). Open-label moxifloxacin served as positive control.
\end{abstract}

Results: The effect of lucerastat on $\triangle \triangle \mathrm{QTCF}$ was predicted as $0.39 \mathrm{~ms}$ ( $90 \%$ confidence interval $[\mathrm{Cl}]-0.13$ to 0.90 ) and $1.69 \mathrm{~ms}(90 \% \mathrm{Cl} 0.33-3.05)$ at lucerastat peak plasma concentration after dosing with $1000 \mathrm{mg}(5.2 \mu \mathrm{g} / \mathrm{mL})$ and $4000 \mathrm{mg}(24.3 \mu \mathrm{g} / \mathrm{mL})$, respectively. A QTcF effect $>10 \mathrm{~ms}$ was excluded up to lucerastat plasma concentrations of approximately $34.0 \mu \mathrm{g} / \mathrm{mL}$. Lucerastat did not exert an effect on other ECG parameters. Across doses, absorption of lucerastat was rapid, its elimination half-life ranged from 8.0 to $10.0 \mathrm{~h}$, and the pharmacokinetics (PK) of lucerastat were dose-proportional. Moxifloxacin PK were in line with published data and assay sensitivity was demonstrated by the moxifloxacin QTc response. Lucerastat was safe and well tolerated.

Conclusions: Lucerastat up to a dose of $4000 \mathrm{mg}$ has no clinically relevant liability to prolong the QT interval or any clinically relevant effect on other ECG parameters. This will be an important factor in the overall benefit-risk assessment of lucerastat in the potential treatment of Fabry disease.

Trial registration The study was registered with the ClinicalTrials.gov identifier NCT03832452 (February 6th, 2019, https ://clinicaltrials.gov/ct2/show/NCT03832452) and the EudraCT number 2018-004546-42 (December 17th, 2018).

\footnotetext{
*Correspondence: markus.mueller@idorsia.com

${ }^{1}$ Department of Clinical Pharmacology, Idorsia Pharmaceuticals Ltd,

Hegenheimermattweg 91,4123 Allschwil, Switzerland

Full list of author information is available at the end of the article
}

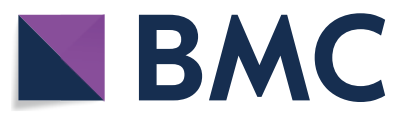

(c) The Author(s) 2020. Open Access This article is licensed under a Creative Commons Attribution 4.0 International License, which permits use, sharing, adaptation, distribution and reproduction in any medium or format, as long as you give appropriate credit to the original author(s) and the source, provide a link to the Creative Commons licence, and indicate if changes were made. The images or other third party material in this article are included in the article's Creative Commons licence, unless indicated otherwise in a credit line to the material. If material is not included in the article's Creative Commons licence and your intended use is not permitted by statutory regulation or exceeds the permitted use, you will need to obtain permission directly from the copyright holder. To view a copy of this licence, visit http://creativecommons.org/licenses/by/4.0/. The Creative Commons Public Domain Dedication waiver (http://creativeco mmons.org/publicdomain/zero/1.0/) applies to the data made available in this article, unless otherwise stated in a credit line to the data. 
Keywords: Lucerastat, Glucosylceramide synthase inhibitor, Fabry disease, QT interval, Thorough QT study

\section{Background}

Fabry disease (FD) is a rare inherited glycosphingolipid storage disorder caused by deleterious mutations in the GLA gene coding for the lysosomal enzyme $\alpha$-galactosidase $A(\alpha-G a l A)$. In patients with $\mathrm{FD}$, the catabolic activity of $\alpha-\mathrm{GalA}$ is either reduced or absent. Therefore, $\alpha$-GalA substrates including globotriaosylceramide, globotriaosylsphingosine, and other neutral glycosphingolipids accumulate in lysosomes and other subcellular compartments. This manifests in progressive malfunction of many cell types and organs, particularly kidneys, heart, nervous system, and skin. Consequently, patients with FD suffer from a broad variety of clinical symptoms, including neuropathic pain, progressive renal disease, cardiomyopathy, stroke, and gastrointestinal disturbances $[1,2]$.

Currently, two therapeutic modalities are approved for the treatment of FD. These are enzyme replacement therapy (ERT) and pharmacological chaperone therapy. Emerging treatment strategies include substrate reduction therapy, mRNA-based therapy, and gene therapy [35]. ERT with bi-weekly infusion of recombinant enzyme, either agalsidase alfa or beta, aims to restore a level of $\alpha$-GalA activity that is enough to clear the cytotoxic globotriaosylceramide accumulation in tissues, thereby preventing, stabilizing, or reversing the progressive decline in the function of affected organs before irreversible damage occurs [6]. Some specific GLA gene mutations can lead to expression of abnormal $\alpha$-GalA that is not effectively delivered into the lysosome. By binding to its active site, pharmacological chaperone therapy with oral migalastat can partially restore $\alpha$-GalA trafficking to the lysosomes and thereby its enzymatic activity in cells of Fabry patients with so-called 'amenable' mutations [7, 8].

Despite the availability of ERT and pharmacological chaperone therapy, there is still a high unmet medical need. Bi-weekly infusion of ERT can be cumbersome and/or associated with tolerability issues, and potentially induces neutralizing antibodies, jeopardizing its effectiveness $[9,10]$. Pharmacological chaperone therapy with migalastat is limited to Fabry patients with specific 'amenable' mutations $[11,12]$.

Substrate reduction therapy aims to prevent accumulation of glycosphingolipids by inhibiting glucosylceramide synthase. This enzyme catalyzes the first committed step of glycosphingolipid biosynthesis and, therefore, substrate reduction therapy can reduce the rate of synthesis of globotriaosylceramide to a level compatible with its residual clearance. The desired outcome is a reduction of net globotriaosylceramide load in tissues leading to symptomatic improvement and a delayed progression towards end-stage organ failure. This therapeutic approach has been proven successful with miglustat for other lysosomal storage disorders. Miglustat is marketed under the tradename Zavesca ${ }^{\circledR}$ and indicated for the treatment of type 1 Gaucher disease and NiemannPick type $\mathrm{C}$ disease. Another substrate reduction therapy, venglustat, has been investigated in a long-term, phase 2 clinical trial (NCT02489344) to evaluate its effectiveness in male patients with FD who completed a previous phase 2 trial (NCT02228460) [4].

Lucerastat ( $N$-butyldeoxygalactonojirimycin or (2R,3S,4R,5S)-1-butyl-2-(hydroxylmethyl) piperidine-3,4,5-triol) is a small iminosugar molecule that is in development to provide oral substrate reduction therapy for FD, independent of the patient's underlying mutation. Inhibition of glucosylceramide synthase by lucerastat dose dependently lowered globotriaosylceramide and lysosomal staining in cultured fibroblasts from Fabry patients, independent of their $\alpha$-GalA genotype [13]. In a phase $1 \mathrm{~b}$ proof-of-concept study, 10 subjects with FD received oral lucerastat (1000 mg twice daily) for 12 weeks on top of ERT and 4 received ERT only [14]. Mean plasma levels of globotriaosylceramide and its precursors glucosylceramide and lactosylceramide were markedly decreased from baseline following treatment with lucerastat (after 12 weeks: $-55.0 \%,-49.0 \%$, and $-32.7 \%$, respectively).

Following single oral doses (ranging between 100 and $1000 \mathrm{mg}$ ) and multiple oral doses (up to $1000 \mathrm{mg}$ twice daily for up to 7 days) the PK of lucerastat in healthy male subjects were dose-proportional and characterized by quick absorption and a short half-life $\left(t_{1 / 2}\right)$ [15]. No accumulation was observed. The PK characteristics of lucerastat in subjects with FD who received $1000 \mathrm{mg}$ lucerastat twice daily for 12 weeks were similar to those observed in healthy subjects [14]. In the phase 1 studies, lucerastat was safe and well tolerated, both in healthy subjects and in patients.

Currently, a double-blind, placebo-controlled phase 3 study is being conducted to determine the efficacy and safety of lucerastat oral monotherapy (1000 mg twice daily) in male and female adult subjects with a diagnosis of FD and Fabry-associated neuropathic pain, independent of their genotype (ClinicalTrials.gov identifier: NCT03425539, EudraCT number: 2017-003369-85).

Nonclinical data including long-term toxicity studies were not indicative of any QT liability of lucerastat or any 
other adverse effect on cardiac function. However, clinical investigation of the potential QT liability is required for all investigational drugs with systemic exposure. In addition, many patients with FD suffer from cardiomyopathies. Rhythm and conduction abnormalities are commonly seen in these patients $[16,17]$. Therefore, this study was conducted to evaluate the effect of lucerastat on the QT/QTc interval, in line with applicable regulatory guidance $[18,19]$, and after consultation with the US Food and Drug Administration Interdisciplinary Review Team who approved both the study design and the approach to the cardiodynamic evaluation.

The primary objective of this thorough QT (TQT) study was to demonstrate that lucerastat at therapeutic and supratherapeutic doses does not exhibit an effect on the QTc interval $>10 \mathrm{~ms}$ based on concentration-QTc analysis as described previously [20] and recommended by regulatory guidance $[18,19]$.

\section{Methods}

\section{Human subject protection}

Both the study protocol and informed consent documents were approved by the local Ethics Committee (Medisch Ethische Toetsings Commissie, Assen, The Netherlands). Written informed consent was obtained from each subject prior to performing any study-mandated procedure. The study was registered with the ClinicalTrials.gov identifier NCT03832452 and the EudraCT number 2018-004546-42. It was conducted at QPS Netherlands B.V. (Groningen, The Netherlands) from January 28th (first screening) to April 22nd, 2019, in accordance with the revised Declaration of Helsinki principles, International Council for Harmonization Good Clinical Practice guidelines, and applicable laws and regulations. The first subject was enrolled (i.e., randomized and dosed) on February 13th, 2019.

\section{Study design and sample size}

This was a single-center, randomized, two-part phase 1 study to assess the effect of single therapeutic and supratherapeutic doses of lucerastat on the QT/QTc interval duration. Part A was conducted as a double-blind, placebo-controlled study in healthy male subjects to determine the supratherapeutic dose of lucerastat to be used in Part B. The latter was conducted as a double-blind (for lucerastat), placebo-controlled, four-way crossover study in healthy male and female subjects including open-label moxifloxacin as a positive control to assess assay sensitivity. Both parts of the study were conducted independently of each other and subjects could only participate in one.

At Screening, subjects' health was assessed based on medical history, previous medications, clinical laboratory tests, physical examination, vital signs, and 12-lead safety ECG. Standard criteria for clinical pharmacology studies in healthy subjects were used, including age between 18 and 55 years, body mass index (BMI) between 18 and $30 \mathrm{~kg} / \mathrm{m}^{2}$, QTcF $<450 \mathrm{~ms}$ for male subjects and $<470 \mathrm{~ms}$ for female subjects, and heart rate $(\mathrm{HR}) \leq 90$ beats per minute (bpm). Fertile males and women of childbearing potential had to apply highly effective contraceptive measures.

This was an inpatient study. On days in the study center, subjects received standardized meals/snacks. On days with scheduled dosing, subjects remained fasted for at least $10 \mathrm{~h}$ prior to and $4 \mathrm{~h}$ after study treatment administration, which took place in the morning. The intake of fluids was not allowed from $1 \mathrm{~h}$ before until $1 \mathrm{~h}$ after study treatment administration except for the $240 \mathrm{~mL}$ of water for study treatment intake; up to $400 \mathrm{~mL}$ were allowed if needed to swallow all lucerastat or placebo capsules. Lucerastat was formulated as size 0 hard gelatin capsules at a dose strength of $250 \mathrm{mg}$. Placebo capsules were identical in appearance to the lucerastat capsules and contained the same inactive excipients.

In Part A, 8 male subjects were randomized to receive either lucerastat or placebo (3:1 ratio) under fasted conditions. This part was conducted because clinical experience with doses higher than the anticipated therapeutic dose of $1000 \mathrm{mg}$ lucerastat twice daily was lacking. Lucerastat or placebo was administered as a single oral dose of $2000 \mathrm{mg}$ on Day 1 and $4000 \mathrm{mg}$ on Day 3 to investigate the safety, tolerability, and PK of both doses for the determination of the supratherapeutic dose for Part B. Subjects were confined to the clinical site from the afternoon of Day-1 until the end of study examination on Day 5 .

In Part B, 36 subjects, at least $30 \%$ of each sex, were to be enrolled to achieve at least 30 evaluable subjects. Based on experience published previously [21, 22], a sample size of 30 evaluable subjects was expected to provide more than $95 \%$ power to exclude that lucerastat causes a QTc effect $>10 \mathrm{~ms}$ at clinically relevant plasma levels as shown by the upper bound of the two-sided $90 \% \mathrm{CI}$ of the predicted effect on $\Delta \Delta \mathrm{QTcF}$ at the observed lucerastat geometric mean maximum plasma concentration $\left(\mathrm{C}_{\max }\right)$. The calculation was based on an assumed underlying effect of lucerastat of $3 \mathrm{~ms}$ and a standard deviation (SD) of change-from-baseline QTcF $(\Delta \mathrm{QTcF})$ of $8 \mathrm{~ms}$. In 4 separate periods, subjects received in a random sequence $(34 \times 4$ Williams squares) [23], under fasted conditions, single oral doses of the following study treatments: $1000 \mathrm{mg}$ lucerastat (anticipated therapeutic dose), $4000 \mathrm{mg}$ lucerastat (supratherapeutic dose), $400 \mathrm{mg}$ open-label moxifloxacin (Avelox ${ }^{\circledR}$ ), and placebo. Each dosing was followed by a 36-h observation period. The 4 periods were separated by a washout period of 8 days and 
an end of study examination took place 2-3 days after the last dosing. In each period, subjects were confined to the clinical site from the afternoon of the day before dosing until the end of the observation period on Day 2.

\section{Sample collection and bioanalysis}

For the determination of lucerastat and moxifloxacin plasma concentrations, about $4 \mathrm{~mL}$ of blood was collected for each analyte pre-dose $(0 \mathrm{~h})$ and $0.5,1,1.5,2$, $2.5,3,3.5,4,6,8,12,16,24$, and $36 \mathrm{~h}$ post-dose by direct venipuncture or via an intravenous catheter placed in an antecubital vein. In Part A, an additional blood sample was taken $48 \mathrm{~h}$ post-dose following administration of $4000 \mathrm{mg}$ lucerastat. For bioanalytical measurement of lucerastat, blood samples were collected into potassium ethylenediaminetetraacetic acid containing tubes, and for moxifloxacin into lithium heparin containing tubes, and cooled on ice. Within 30 min after collection, blood samples were centrifuged at $4{ }^{\circ} \mathrm{C}$ at $1500 \mathrm{~g}$ for $10 \mathrm{~min}$. Plasma was aliquoted into polypropylene tubes and stored at $-20{ }^{\circ} \mathrm{C}$ or below. Plasma concentrations of lucerastat were determined using a validated liquid chromatography coupled to tandem mass spectrometry assay [15]; the lower limit of quantification (LLOQ) was $50 \mathrm{ng} / \mathrm{mL}$. For lucerastat, the inter-batch precision was $\leq 4.1 \%$ and the inter-batch accuracy was in the range from -1.2 to $1.1 \%$. Plasma concentrations of moxifloxacin were determined using a validated liquid chromatography method coupled to tandem mass spectrometry detection after protein precipitation; the LLOQ was $10 \mathrm{ng} / \mathrm{mL}$. For moxifloxacin, the inter-batch precision was $\leq 7.3 \%$ and the interbatch accuracy was in the range from -5.1 to $4.4 \%$.

\section{Pharmacokinetic assessments}

The plasma PK parameters of lucerastat and moxifloxacin were derived by noncompartmental analysis (Phoenix WinNonlin version 8.0; Pharsight Corp., Mountain View, CA, USA). The measured individual plasma concentrations were used to directly obtain $C_{\max }$ and the time to reach $C_{\max }\left(t_{\max }\right)$. The area under the plasma concentration-time curve from zero to time $\mathrm{t}\left(\mathrm{AUC}_{0-\mathrm{t}}\right)$ was calculated according to the linear trapezoidal rule, using the last measured concentration above the LLOQ. All plasma concentration values below the LLOQ were set to zero. The area under the curve from zero to infinity $\left(\mathrm{AUC}_{0-\infty}\right)$ was calculated by combining $\mathrm{AUC}_{0-\mathrm{t}}$ and $\mathrm{AUC}_{\text {extra }}$, where $\mathrm{AUC}_{\text {extra }}$ represented an extrapolated value obtained by the last measured plasma concentration above LLOQ divided by the terminal elimination rate constant $\left(\lambda_{z}\right)$. The $t_{1 / 2}$ was calculated as $\ln 2 / \lambda_{z}$. The assumption was made that $C_{\max }, A U C$, and $t_{1 / 2}$ were lognormally distributed.

\section{ECG methodology}

Cardiodynamic evaluation with ECGs extracted from continuous (Holter) recordings was performed in Part $\mathrm{B}$ only. The continuous recording was performed in each period, running from approximately $1 \mathrm{~h}$ pre-dose on Day 1 until $36 \mathrm{~h}$ post-dose on Day 2. ECGs were recorded using an M12R digital 12-lead Holter recorder (Global Instrumentation, Manlius, NY, USA). Data were stored on memory cards. At the ECG service provider eResearch Technology Inc. (ERT ${ }^{\circledR}$, Rochester, NY, USA), replicate, nonoverlapping 14-s ECGs were extracted in close succession within each pre-defined extraction window related to study treatment administration on Day 1 (i.e., $0.75,0.5$, and $0.25 \mathrm{~h}$ pre-dose; $0.5,1,1.5,2,2.5,3,3.5$, $4,6,8,12,24$, and $36 \mathrm{~h}$ post-dose) using the proprietary method TQT Plus ${ }^{\circledR}\left(\right.$ ERT $^{\circledR}$, Rochester, NY, USA). This enabled the extraction of a high-quality data set by identifying periods of recordings with the lowest available HR variability and noise. The average of the 3 pre-dose time points on Day 1 of each period was used as baseline. Subjects were resting in a supine position for a minimum of $15 \mathrm{~min}$ at each time point of ECG reading $(10 \mathrm{~min}$ before and 5 min during ECG reading). ECG intervals were measured using the Expert Precision QT technique (formerly described as High-Precision QT analysis) [24]. ECG analysts at the central lab were blinded to subject, visit, and study treatment. The same analyst was assigned for all ECGs of a given subject using lead II as the primary analysis lead in a process overseen by an experienced cardiologist. The QT and preceding RR value for each beat was used for HR correction; QTcF was derived using Fridericia's formula defined as QTcF $=\mathrm{QT} / \mathrm{RR}^{1 / 3}$. The median value of each ECG parameter from the set of evaluable beats in each extracted replicate was calculated and then the mean of all available medians, at minimum 3 medians, from the nominal time point was used as the subject's reportable value at that time point.

\section{Safety assessments}

Safety and tolerability were evaluated based on reporting of treatment-emergent AEs (TEAEs) regardless of causality, clinical laboratory tests, vital signs, physical examinations, and 12-lead safety ECGs to detect any immediate ECG effects. AEs were coded using the Medical Dictionary for Regulatory Activities (MedDRA version 22.0). The relationship to study treatment and the intensity of TEAEs was judged by the investigator.

\section{Statistical analysis}

The primary analysis was based on concentration-QTc modeling of the relationship between lucerastat plasma concentration and $\Delta \mathrm{QTCF}$ with the intent to exclude an 
effect $>10 \mathrm{~ms}$ at clinically relevant plasma concentrations. This relationship was quantified using a linear mixedeffects modeling approach with $\Delta \mathrm{QTcF}$ as dependent variable, drug plasma concentration as explanatory variate $(0$ for placebo), centered baseline QTcF (i.e., baseline QTcF for an individual subject minus the population mean baseline QTcF for all subjects) as an additional covariate, study treatment (active $=1$ or placebo $=0$ ) and time as categorical factors, and a random intercept and slope per subject following statistical approaches described previously [20]. Additional exploratory analyses via graphical displays and/or model fitting included assessment for a delayed effect known as hysteresis and the justification for the choice of the concentration-QTc model. The term placebo-adjusted $\Delta \mathrm{QTcF}$ in the concentration-QTc analysis was used to illustrate the underlying data on a subject level. It reflected the observed individual $\triangle \mathrm{QTcF}$ on active treatment (lucerastat or moxifloxacin) or placebo minus the estimated mean $\Delta \mathrm{QTcF}$ on placebo [20].

Assay sensitivity was evaluated by concentration-QTc analysis of the effect of $400 \mathrm{mg}$ open-label moxifloxacin on $\Delta \Delta \mathrm{QTCF}$ using a similar model as for the primary analysis. Assay sensitivity was deemed demonstrated if the slope of the moxifloxacin concentration-QTc relationship was statistically significant at the $10 \%$ level in a 2-sided test and the model-predicted QT effect was greater than $5 \mathrm{~ms}$ (i.e., the lower bound of the 2-sided $90 \% \mathrm{CI}$ of $\Delta \Delta \mathrm{QTCF}$ ) at the observed geometric mean $\mathrm{C}_{\max }$.

In addition, the effects of study treatment on $\Delta \Delta \mathrm{QTcF}$, $\Delta \Delta \mathrm{HR}, \Delta \Delta \mathrm{PR}$, and $\Delta \Delta \mathrm{QRS}$ were evaluated at each postdose time point (by-time point analysis) using the intersection union test. The by-time point analysis for QTcF was also based on a linear mixed-effects model with $\triangle \mathrm{QTcF}$ as the dependent variable; period, sequence, time, study treatment, and time-by-treatment interaction as fixed effects; and baseline QTcF as a covariate. The same by-time point analysis model was used for HR, PR, and QRS as described for QTcF above. An unstructured covariance matrix was specified for the repeated measures at post-dose time points for subject within treatment period. From this analysis, the Least Squares (LS) mean and 2-sided $90 \%$ CI were calculated for the contrasts 'lucerastat versus placebo' at each dose of lucerastat and each post-dose time point, separately. The same was performed for moxifloxacin.

An analysis of categorical outliers was performed for changes in HR, PR, QRS, QTcF, T-wave morphology, and presence of $\mathrm{U}$-waves. Categorical QTcF outliers were defined as QTcF values $>450$ to $\leq 480,>480$ to $\leq 500$, or $>500 \mathrm{~ms}$ and were analyzed descriptively, along with QTcF increases from baseline (defined as $>30$ to $\leq 60$ or $>60 \mathrm{~ms}$ ).
Continuous demographic variables were summarized by descriptive statistics (mean $\pm \mathrm{SD}$ ), qualitative demographic characteristics were summarized by percentages, AEs and other safety parameters were summarized descriptively. In addition, PK parameters of lucerastat were summarized using geometric mean and two-sided 95\% CI or median and range for $t_{\max }$.

All statistical analyses were performed using SAS $^{\circledR}$ software (version 9.4 or higher; SAS Institute, Cary, NC, USA).

\section{Results}

\section{Subject demographics and disposition}

In Part A, 8 White male subjects were enrolled. All completed the study. The overall mean age was 31.8 years (range: $18-54$ years) and the mean BMI was $23.4 \mathrm{~kg} / \mathrm{m}^{2}$ (range: $19.9-28.1 \mathrm{~kg} / \mathrm{m}^{2}$ ). There was no relevant imbalance in demographic characteristics between the subjects receiving lucerastat or placebo (data not shown). In Part B, 36 subjects were enrolled; 22 were females and 14 males. Of these, 24 were White, 9 Black or African American, 1 Asian, 1 Hispanic or Latino, and 1 mixed Aruban. The overall mean age was 29.6 years (range: $18-54$ years) and the mean BMI was $23.9 \mathrm{~kg} / \mathrm{m}^{2}$ (range: $19.3-29.4 \mathrm{~kg} /$ $\mathrm{m}^{2}$ ). One female subject was not dosed with open-label moxifloxacin in the 4th period due to difficulties in placing the cannula for blood withdrawals. Consequently, none of the scheduled assessments were performed. Therefore, data was available from 36 subjects on each dose of lucerastat and on placebo, and from 35 subjects on moxifloxacin.

\section{Pharmacokinetics}

A summary of lucerastat and moxifloxacin PK parameters is presented in Table 1. Across all doses, lucerastat was rapidly absorbed with peak plasma concentrations occurring between 0.5 and $4.0 \mathrm{~h}$ after dosing. Geometric mean $t_{1 / 2}$ ranged from 8.0 to $10.0 \mathrm{~h}$. The exposure to lucerastat increased dose-proportionally, i.e., was about 2and 4.5-fold higher for $\mathrm{C}_{\max }$ and AUC upon dosing with $4000 \mathrm{mg}$ as compared to $2000 \mathrm{mg}$ in Part A and $1000 \mathrm{mg}$ in Part B, respectively. Mean plasma concentration-time profiles of lucerastat following single-dose administration in both parts are shown in Fig. 1. Based on PK and safety data, $4000 \mathrm{mg}$ lucerastat was selected as the supratherapeutic dose to investigate the effect of lucerastat on cardiac repolarization in Part B. Peak plasma concentrations of moxifloxacin were reached at $2.0 \mathrm{~h}$ post-dose (median). Geometric mean $\mathrm{C}_{\max }$ and $\mathrm{AUC}_{0-\mathrm{t}}$ for moxifloxacin were $3.0 \mu \mathrm{g} / \mathrm{mL}$ and $32.6 \mu \mathrm{g} \cdot \mathrm{h} / \mathrm{mL}$, respectively. Geometric mean $t_{1 / 2}$ was $10.4 \mathrm{~h}$ [Table 1]. 
Table 1 Summary of lucerastat and moxifloxacin PK parameters

\begin{tabular}{|c|c|c|c|}
\hline \multirow[t]{3}{*}{ PK parameter (unit) } & \multicolumn{2}{|l|}{ Lucerastat } & \\
\hline & $2000 \mathrm{mg}$ & $4000 \mathrm{mg}$ & \\
\hline & $n=6$ & $\mathrm{n}=6$ & \\
\hline \multicolumn{4}{|l|}{ Part A } \\
\hline$C_{\max }(\mu \mathrm{g} / \mathrm{mL})$ & $11.3(9.9,13.0)$ & $22.1(17.6,27.7)$ & \\
\hline $\mathrm{t}_{\max }(\mathrm{h})$ & $2.8(1.5,4.0)$ & $3.3(2.5,4.0)$ & \\
\hline$A \cup C_{0-t}(\mu \mathrm{g} \cdot \mathrm{h} / \mathrm{mL})$ & $93.9(75.7,116.5)$ & $193.7(163.8,229.1)$ & \\
\hline $\mathrm{AUC}_{0-\infty}(\mu \mathrm{g} \cdot \mathrm{h} / \mathrm{mL})$ & $98.1(79.8,120.5)$ & $198.8(167.7,235.5)$ & \\
\hline$t_{1 / 2}(h)$ & $8.0(5.8,11.0)$ & $9.3(7.1,12.2)$ & \\
\hline \multirow[t]{3}{*}{ PK parameter (unit) } & \multicolumn{2}{|l|}{ Lucerastat } & Moxifloxacin \\
\hline & $1000 \mathrm{mg}$ & $4000 \mathrm{mg}$ & $400 \mathrm{mg}$ \\
\hline & $n=36$ & $n=36$ & $n=35$ \\
\hline \multicolumn{4}{|l|}{ Part B } \\
\hline$C_{\max }(\mu \mathrm{g} / \mathrm{mL})$ & $5.2(4.9,5.6)$ & $24.3(22.8,26.0)$ & $3.0(2.7,3.3)$ \\
\hline$t_{\max }(h)$ & $2.5(1.5,4.0)$ & $2.5(0.5,4.0)$ & $2.0(0.5,6.0)$ \\
\hline$A \cup C_{0-t}(\mu \mathrm{g} \cdot \mathrm{h} / \mathrm{mL})$ & $42.1(39.8,44.6)$ & $191.1(183.2,199.2)$ & $32.6(30.1,35.4)$ \\
\hline$A \cup C_{0-\infty}(\mu \mathrm{g} \cdot \mathrm{h} / \mathrm{mL})$ & $45.0(42.4,47.7)$ & $199.3(190.9,207.9)$ & $35.9(33.0,39.2)$ \\
\hline$t_{1 / 2}(h)$ & $10.0(9.1,11.0)$ & $8.2(7.6,8.9)$ & $10.4(9.7,11.1)$ \\
\hline
\end{tabular}

Data expressed as geometric mean $(95 \% \mathrm{Cl})$ or as median (range) for $t_{\max }$

$\mathrm{AUC}_{0-\infty}$, area under the plasma drug concentration-time curve (from time zero to infinity); $A \cup \mathrm{C}_{0-\mathrm{t}}$, area under the plasma drug concentration-time curve (from time zero to time $t$ of the last measured concentration above the limit of quantification); $\mathrm{Cl}$, confidence interval; $\mathrm{C}_{\max }$ maximum plasma concentration; $\mathrm{n}$, number of subjects with available data; $\mathrm{PK}$, pharmacokinetic; $t_{1 / 2}$, half-life; $t_{\max }$, time to maximum plasma concentration

\section{Cardiodynamic ECG analysis}

ECG parameters were well balanced across study treatments with mean HR between 61.5 and $63.5 \mathrm{bpm}, \mathrm{QTcF}$ between 403.0 and $406.5 \mathrm{~ms}$, PR between 143.0 and $145.0 \mathrm{~ms}$, and QRS between 102.5 and $102.8 \mathrm{~ms}$.

Lucerastat at single oral doses of 1000 and $4000 \mathrm{mg}$ did not exert an effect on HR. The LS mean $\triangle \mathrm{HR}$ on active treatment closely followed the pattern observed with placebo (Fig. 2a). Consequently, LS mean $\Delta \Delta \mathrm{HR}$ varied within a narrow range across all post-dose time points following administration of lucerastat, i.e., between -1.8 and $0.8 \mathrm{bpm}$ (Fig. 2b).

By-time point analysis across all post-dose time points following administration of 1000 and $4000 \mathrm{mg}$ lucerastat showed that the LS mean $\triangle \mathrm{QTCF}$ on lucerastat closely followed the diurnal pattern observed on placebo with a reduction of $\triangle \mathrm{QTCF}$ observed with all study treatments at 6 and $8 \mathrm{~h}$ post-dose (Fig. 3a). Consequently, the LS mean $\Delta \Delta$ QTcF on lucerastat varied between -2.3 and $2.6 \mathrm{~ms}$, without an indication of dose-dependency (Fig. 3b, Table 2). For both lucerastat doses, $\mathrm{C}_{\max }$ and peak LS mean $\Delta \Delta \mathrm{QTCF}$ occurred at $2.5 \mathrm{~h}$ post-dose, demonstrating the lack of hysteresis. In contrast to lucerastat, $400 \mathrm{mg}$ oral moxifloxacin caused a clear QTc prolongation resulting in an increase of the LS mean $\Delta \Delta \mathrm{QTcF}$ across post-dose time points with a peak value of $13.9 \mathrm{~ms}$ at $1.5 \mathrm{~h}$ post-dose and a lower bound of the $90 \% \mathrm{CI}$ above $5 \mathrm{~ms}$ from 1 to $12 \mathrm{~h}$ post-dose (Fig. 3b, Table 2).

In the concentration-QTc analysis, a linear model with a treatment effect-specific intercept was fitted for lucerastat plasma concentrations, which represented the data in an acceptable way. The relationship between the individually observed lucerastat plasma concentrations and estimated placebo-adjusted $\triangle \mathrm{QTCF}$ is shown in Fig. 4a (left panel). As depicted in Fig. 4a (right panel) and Table 3, the estimated population slope of the lucerastat concentration-QTc relationship was shallow and statistically significant, i.e., $0.07 \mathrm{~ms}$ per $\mu \mathrm{g} / \mathrm{mL}(90 \% \mathrm{CI}$ $0.01-0.13 ; p=0.0618$ ) with a negligible, statistically nonsignificant treatment effect-specific intercept of $0.03 \mathrm{~ms}$ (90\% CI $-0.51-0.57 ; p=0.9307)$. Using this concentration-QTc relationship, the effect of lucerastat on $\Delta \Delta \mathrm{QTcF}$ was predicted to $0.39 \mathrm{~ms}(90 \% \mathrm{CI}-0.13$ to 0.90$)$ and $1.69 \mathrm{~ms}$ (90\% CI 0.33-3.05) at the observed geometric mean lucerastat $C_{\max }$ upon dosing with $1000 \mathrm{mg}(5.2 \mu \mathrm{g} /$ $\mathrm{mL})$ and $4000 \mathrm{mg}(24.3 \mu \mathrm{g} / \mathrm{mL})$, respectively. By looking at the upper bound of the $90 \%$ CI of the predicted effect (Fig. 4a, right panel), a QTcF effect above $10 \mathrm{~ms}$ could be excluded within the full range of lucerastat plasma concentrations, up to approximately $34 \mu \mathrm{g} / \mathrm{mL}$.

The relationship between the individually observed moxifloxacin plasma concentrations and estimated 

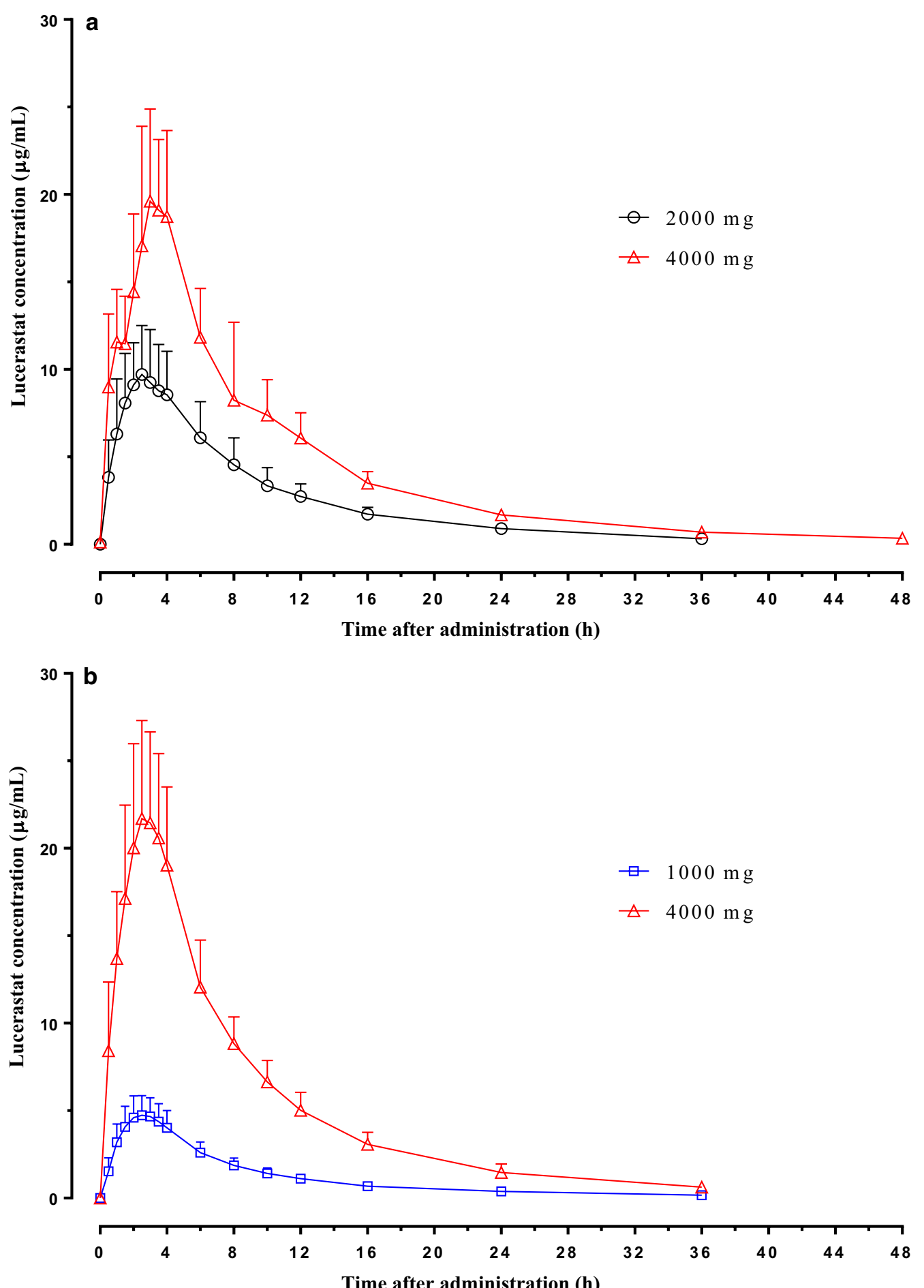

Fig. 1 Plasma concentration-time profiles of lucerastat. Exposure to lucerastat increased approximately dose-proportionally and was characterized by rapid absorption and quick elimination. a Healthy male subjects after administration of 2000 and 4000 mg in Part $A(N=6)$. b Healthy male and female subjects after administration of 1000 and $4000 \mathrm{mg}$ in Part B (N=36). Data expressed as arithmetic mean (+SD). N, number of subjects in the population; SD, standard deviation 

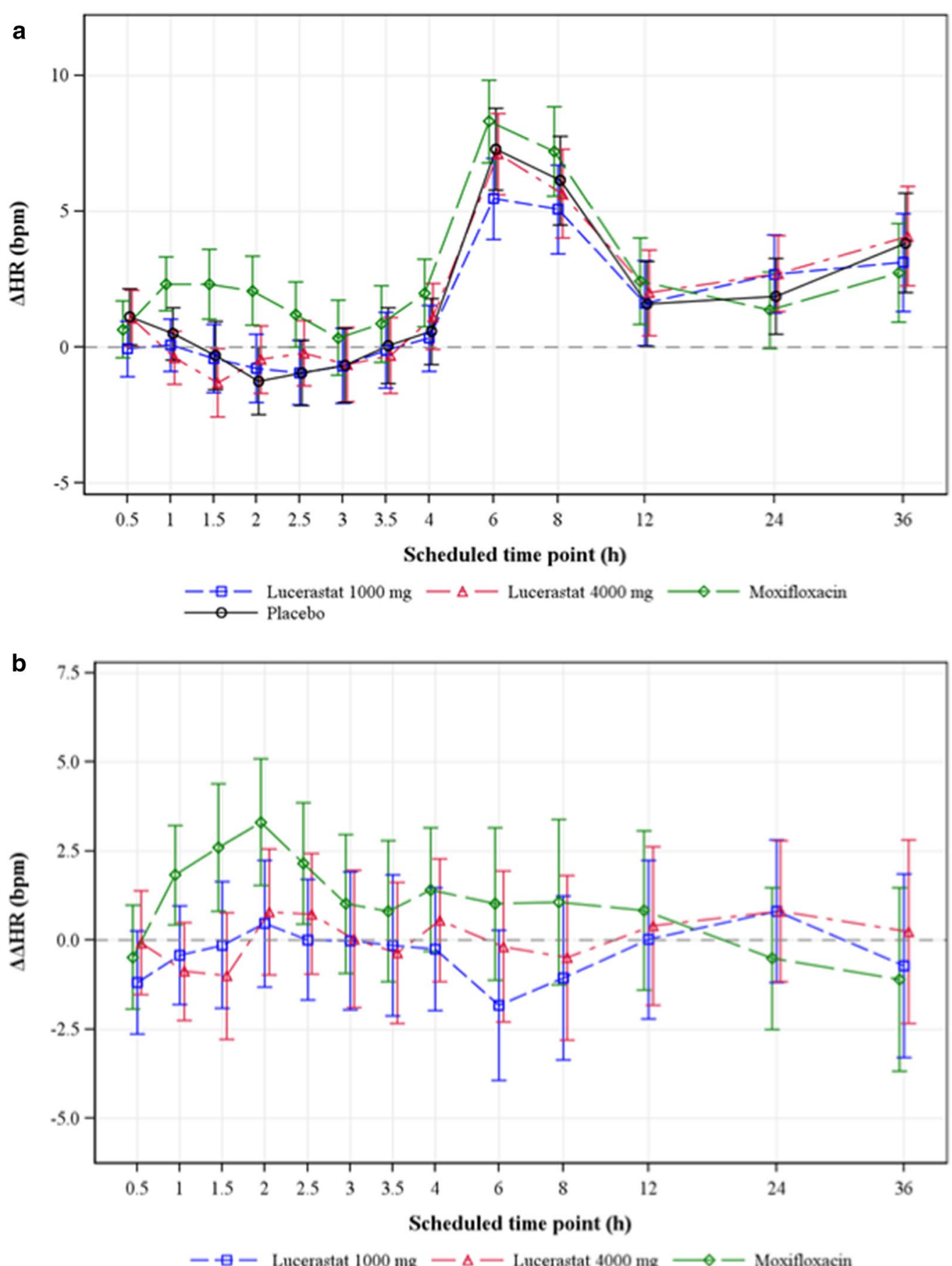

Fig. 2 Change-from-baseline in HR across time points and study treatments. Mean $\Delta H R$ on lucerastat and moxifloxacin closely followed the pattern observed on placebo. a Effect of study treatments on $\triangle H R$. $\mathbf{b}$ Effect of study treatments on $\triangle \Delta H R$. Data expressed as $L S$ mean and $90 \%$ $\mathrm{Cl}$ based on a linear mixed-effects model. bpm, beats per minute; $\mathrm{Cl}$, confidence interval; $\Delta$, change-from-baseline; $\Delta \Delta$, placebo-corrected change-from-baseline; $\mathrm{HR}$, heart rate; $\mathrm{LS}$, least squares

placebo-adjusted $\triangle \mathrm{QTcF}$ is shown in Fig. 4b (left panel). The estimated population slope of the moxifloxacin concentration-QTc relationship was $4.47 \mathrm{~ms}$ per $\mu \mathrm{g} / \mathrm{mL}(90 \%$ CI 3.58-5.36); with a treatment effect-specific intercept of $2.89 \mathrm{~ms}$ (90\% CI 1.82-3.97). Both the treatment effectspecific intercept and the slope of the relationship were statistically significant $(p<0.0001)$. The lower bound of the two-sided $90 \% \mathrm{CI}$ of the predicted $\Delta \Delta \mathrm{QTcF}$ effect 

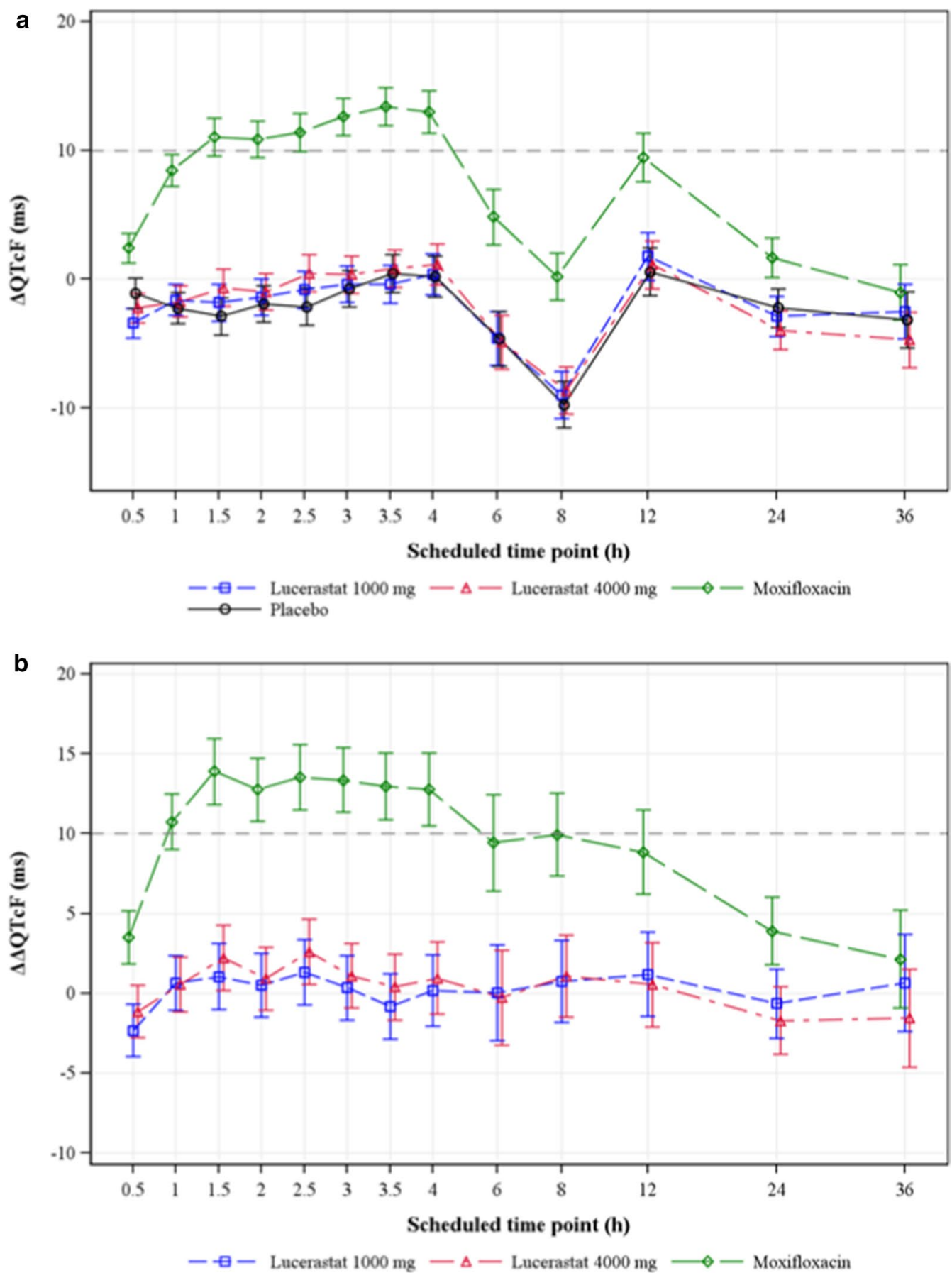

Fig. 3 Change-from-baseline in QTcF across time points and study treatments. Mean $\triangle$ QTcF on lucerastat closely followed the pattern observed on placebo with no indication of dose dependency, whereas moxifloxacin caused a clear QTc prolongation. a Effect of study treatments on $\triangle Q T C F$. $\mathbf{b}$ Effect of study treatments on $\triangle \triangle Q T C F$. Data expressed as $L S$ mean and $90 \% \mathrm{Cl}$ based on a linear mixed-effects model. The dashed black lines represent the threshold for clinically concerning QTc prolongation. Cl, confidence interval; $\Delta$, change-from-baseline; $\Delta \Delta$, placebo-corrected change-from-baseline; LS, least squares; QTcF, Fridericia-corrected QTC

(16.35 ms [90\% CI 14.03-18.68]) at the geometric mean moxifloxacin $\mathrm{C}_{\max }(3.0 \mu \mathrm{g} / \mathrm{mL}$ ) was above $5 \mathrm{~ms}$ (Fig. $4 \mathrm{~b}$ right panel, Table 3).
Lucerastat at single oral doses of 1000 and $4000 \mathrm{mg}$ did not have a clinically relevant effect on cardiac conduction, i.e., PR and QRS intervals (data not shown). 
Table $2 \Delta \Delta Q T c F$ across study treatments and post-dose time points

\begin{tabular}{|c|c|c|c|}
\hline \multirow{3}{*}{$\begin{array}{l}\text { Time post- } \\
\text { dose (h) }\end{array}$} & \multicolumn{2}{|l|}{ Lucerastat } & \multirow{3}{*}{$\begin{array}{l}\text { Moxifloxacin } \\
\begin{array}{l}400 \mathrm{mg} \\
\mathrm{n}=35\end{array}\end{array}$} \\
\hline & $1000 \mathrm{mg}$ & $4000 \mathrm{mg}$ & \\
\hline & $n=36$ & $n=36$ & \\
\hline 0.5 & $-2.3(-4.0,-0.7)$ & $-1.1(-2.8,0.5)$ & $3.5(1.9,5.2)$ \\
\hline 1.0 & $0.7(-1.0,2.4)$ & $0.5(-1.2,2.3)$ & $10.7(9.0,12.5)$ \\
\hline 1.5 & $1.1(-1.0,3.1)$ & $2.2(0.2,4.3)$ & $13.9(11.8,16.0)$ \\
\hline 2.0 & $0.5(-1.5,2.5)$ & $0.9(-1.0,2.9)$ & $12.8(10.8,14.8)$ \\
\hline 2.5 & $1.3(-0.7,3.4)$ & $2.6(0.6,4.7)$ & $13.5(11.5,15.6)$ \\
\hline 3.0 & $0.4(-1.7,2.4)$ & $1.1(-0.9,3.1)$ & $13.4(11.3,15.4)$ \\
\hline 3.5 & $-0.8(-2.9,1.3)$ & $0.4(-1.7,2.5)$ & $13.0(10.9,15.1)$ \\
\hline 4.0 & $0.2(-2.1,2.4)$ & $1.0(-1.3,3.2)$ & $12.8(10.5,15.1)$ \\
\hline 6.0 & $0.0(-3.0,3.0)$ & $-0.3(-3.3,2.7)$ & $9.4(6.4,12.5)$ \\
\hline 8.0 & $0.7(-1.8,3.3)$ & $1.1(-1.5,3.7)$ & $9.9(7.3,12.5)$ \\
\hline 12.0 & $1.2(-1.4,3.8)$ & $0.6(-2.1,3.2)$ & $8.9(6.2,11.5)$ \\
\hline 24.0 & $-0.6(-2.8,1.5)$ & $-1.7(-3.8,0.4)$ & $3.9(1.8,6.0)$ \\
\hline 36.0 & $0.7(-2.4,3.7)$ & $-1.5(-4.6,1.5)$ & $2.1(-0.9,5.2)$ \\
\hline
\end{tabular}

Data expressed as LS means $(90 \% \mathrm{Cl})$ in $\mathrm{ms}$

$\mathrm{Cl}$, confidence interval; $\Delta$, change-from-baseline; $\Delta \Delta$, placebo-corrected change-from-baseline; $E C G$, electrocardiography; $L S$, least squares; $n$, number of subjects receiving lucerastat or moxifloxacin with available data; QTcF, Fridericiacorrected QTC

No outliers in terms of HR were observed except for 1 subject with HR below $50 \mathrm{bpm}$ with a decreasefrom-baseline $>25 \%$ at 1 time point after administration of $1000 \mathrm{mg}$ lucerastat. A QTcF value between 450 and $480 \mathrm{~ms}$ was observed in 3 subjects ( 1 on lucerastat $4000 \mathrm{mg}, 2$ on moxifloxacin, and 1 on placebo). There were no subjects with QTcF $>480 \mathrm{~ms}$ or $\Delta \mathrm{QTcF}>30 \mathrm{~ms}$. No treatment-emergent $\mathrm{T}$-wave morphology changes were observed except for 3 observations of negative T-waves that occurred in the same subject at 1 time point each after administration of lucerastat $1000 \mathrm{mg}$, moxifloxacin, and placebo. No presence of $\mathrm{U}$-waves was observed.

\section{Safety and tolerability}

Lucerastat at single oral doses of 1000, 2000, and $4000 \mathrm{mg}$ was safe and well tolerated. Moxifloxacin at a single oral dose of $400 \mathrm{mg}$ was also safe and well tolerated. A summary of TEAEs reported in both parts is presented in Table 4. No serious AEs or any AEs leading to study treatment/study discontinuation were reported.

On Day 1 in Part A, 1 subject on 2000 mg lucerastat and 1 subject on placebo reported each 2 TEAEs. No TEAE was reported following administration of $4000 \mathrm{mg}$ lucerastat.

In Part B, 12 subjects on $1000 \mathrm{mg}$ lucerastat, 9 subjects on $4000 \mathrm{mg}$ lucerastat, 18 subjects on $400 \mathrm{mg}$ moxifloxacin, and 9 subjects on placebo reported at least one TEAE. There were no clear differences in the incidence of TEAEs across doses of lucerastat or as compared to placebo. All TEAEs were graded by the investigator as mild in intensity and the most commonly reported TEAE was headache.

Overall, 9 treatment-emergent ECG abnormalities in 3 out of 36 subjects were judged by the investigator as clinically significant (8 after administration of $400 \mathrm{mg}$ moxifloxacin, 1 after administration of $4000 \mathrm{mg}$ lucerastat). These abnormalities were reported as TEAEs of 'ECG QT prolonged' as displayed in Table 4. Eight occurred following administration of $400 \mathrm{mg}$ moxifloxacin in 3 out of 35 subjects $(8.6 \%)$. One occurred following administration of $4000 \mathrm{mg}$ lucerastat in 1 out of 36 subjects $(2.8 \%)$. This subject showed a QTcF of $452 \mathrm{~ms}$ (+12 ms from baseline) at $2.5 \mathrm{~h}$ and again at $36 \mathrm{~h}$ after administration of $4000 \mathrm{mg}$ lucerastat, where at the latter time point the investigator judged the excursion as not clinically significant. Considering that (a) the QTcF interval for this subject was only marginally above the upper limit of normal of $450 \mathrm{~ms}$; (b) the change-from-baseline for QTcF was below $30 \mathrm{~ms}$; (c) the increase occurred at the same magnitude also at $36 \mathrm{~h}$ post-dose, which was not considered clinically significant; and (d) this increase was not observed in the analysis of the continuous 24-h Holter ECG recording, these ECG findings were considered as not clinically relevant.

No clinically relevant changes in vital signs, body weight, or laboratory variables were identified upon administration of single oral doses of up to $4000 \mathrm{mg}$ lucerastat.

\section{Discussion}

This TQT study investigated the effect of the glucosylceramide synthase inhibitor lucerastat on cardiac repolarization. It was conducted as a prospective, single-center, randomized, double-blind (for lucerastat), placebocontrolled, two-part phase 1 study in healthy subjects. The selection of healthy subjects was justified on the basis that safety, tolerability, and PK can be investigated accurately in this population, without interference from concomitant diseases or medication. Part A was a pilot study in healthy male subjects to determine the supratherapeutic dose of lucerastat for Part B. Only male subjects were included in Part A to have a more homogeneous population and to avoid any potential variability in PK parameters due to menstrual cycle. Part B was a four-way crossover study in healthy male and female subjects including a therapeutic and supratherapeutic dose of lucerastat, open-label moxifloxacin as a positive, and placebo as a negative control. Using a healthy subject population is in line with regulatory guidance, which states that the TQT study is typically carried out in 

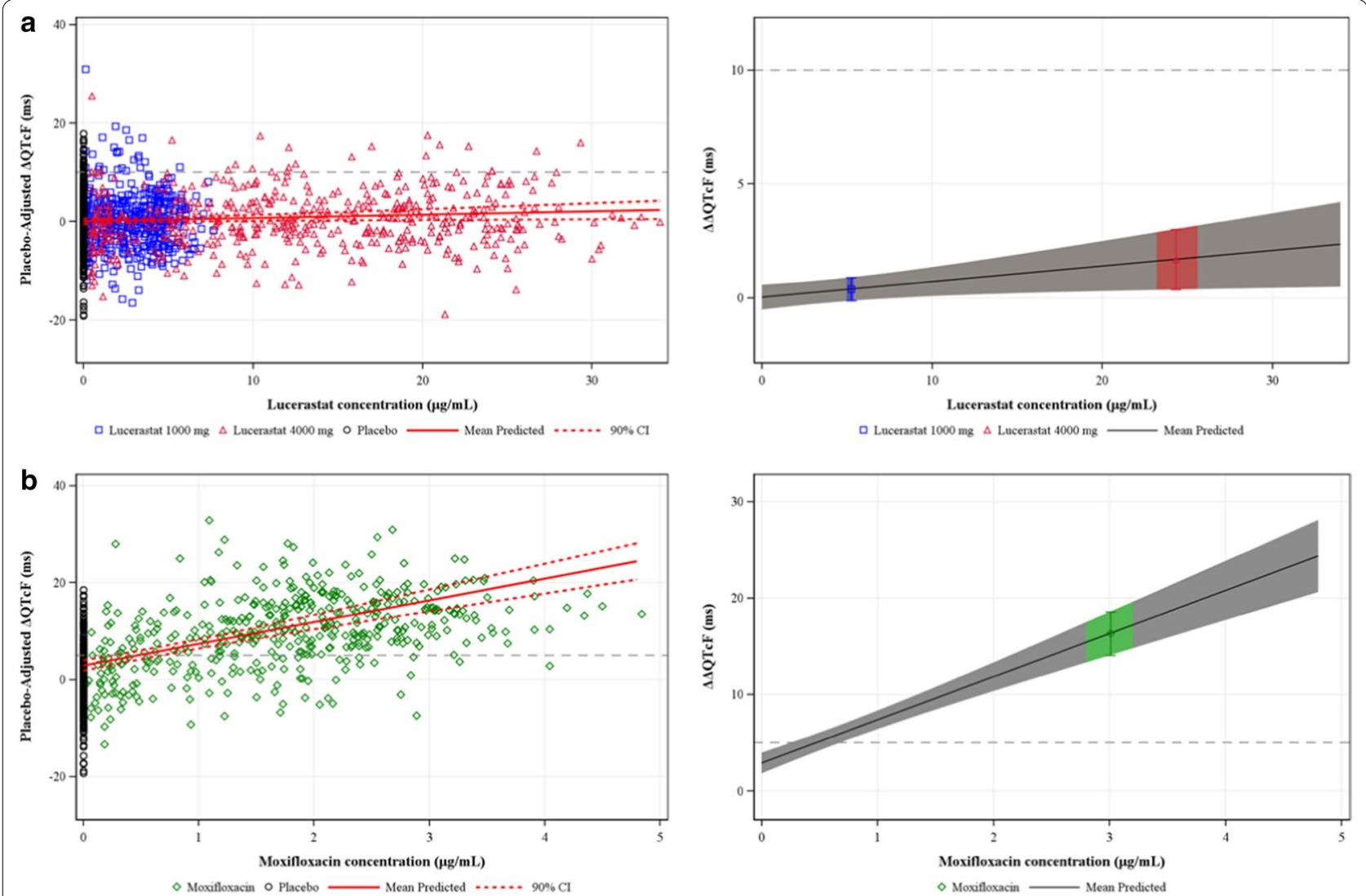

Fig. 4 Concentration-QTc analysis. A linear model with a treatment effect-specific intercept was fitted for lucerastat and moxifloxacin plasma concentrations. For lucerastat, a QTcF effect above $10 \mathrm{~ms}$ could be excluded up to a plasma concentration of approximately $34 \mu \mathrm{g} / \mathrm{mL}$, whereas moxifloxacin caused a clear QTc prolongation. a Lucerastat and $\mathbf{b}$ moxifloxacin. Left panel: scatter plots of observed plasma concentrations and estimated placebo-adjusted $\triangle \mathrm{QTCF}$ by subject. The solid red lines with dashed red lines denote the predicted mean $\triangle \Delta \mathrm{QTCF}$ with $90 \% \mathrm{Cl}$. The blue squares, red triangles, and black circles denote the pairs of observed lucerastat plasma concentrations and estimated placebo-adjusted $\triangle \mathrm{QTCF}$ by subject for lucerastat $1000 \mathrm{mg}$, lucerastat $4000 \mathrm{mg}$, and placebo, respectively (a). The green diamonds and black circles denote the pairs of observed moxifloxacin plasma concentrations and estimated placebo-adjusted $\triangle Q T c F$ by subject for moxifloxacin and placebo, respectively (b). Right panel: relationship between lucerastat (a) and moxifloxacin (b) plasma concentrations and predicted $\Delta \Delta \mathrm{QTCF}$. The solid black lines with gray shaded area denote the predicted mean $(90 \% \mathrm{Cl}) \Delta \Delta \mathrm{QTcF}$. The blue, red, and green areas denote the predicted mean $(90 \% \mathrm{Cl}) \Delta \Delta \mathrm{QTCF}$ with blue square, red triangle, and green diamond at the geometric mean $(90 \% \mathrm{Cl}) \mathrm{C}_{\max }$ of lucerastat $1000 \mathrm{mg}$, lucerastat $4000 \mathrm{mg}$, and moxifloxacin $400 \mathrm{mg}$, respectively. The dashed black lines represent the thresholds for clinically concerning QTc prolongation (a) and for demonstrating assay sensitivity (b). $C$, confidence interval; $C_{\text {max }}$ maximum plasma concentration; $\Delta$, change-from-baseline; $\Delta \Delta$, placebo-corrected change-from-baseline; $Q T c F$, Fridericia-corrected QTC

Table 3 Summary of concentration-QTc analysis

\begin{tabular}{|c|c|c|c|c|}
\hline Study treatment & $\begin{array}{l}\text { Geometric mean } C_{\max } \\
(90 \% \mathrm{Cl})(\mu \mathrm{g} / \mathrm{mL})\end{array}$ & $\begin{array}{l}\Delta \Delta Q T c F \text { Estimate } \\
(90 \% \mathrm{Cl})(\mathrm{ms})\end{array}$ & $\begin{array}{l}\text { Concentration-QTc slope } \\
(90 \% \mathrm{Cl})(\mathrm{ms} \text { per } \mu \mathrm{g} / \mathrm{mL})\end{array}$ & $\begin{array}{l}\text { Treatment effect- } \\
\text { specific intercept } \\
(90 \% \mathrm{Cl})(\mathrm{ms})\end{array}$ \\
\hline \multicolumn{5}{|l|}{ Lucerastat } \\
\hline 1000 mg & $5.2(4.96,5.55)$ & $0.39(-0.13,0.90)$ & \multirow{2}{*}{$\begin{array}{l}0.07(0.01,0.13) \\
p=0.0618\end{array}$} & \multirow{2}{*}{$\begin{array}{l}0.03(-0.51,0.57) \\
p=0.9307\end{array}$} \\
\hline $4000 \mathrm{mg}$ & 24. $3(23.05,25.68)$ & $1.69(0.33,3.05)$ & & \\
\hline \multicolumn{5}{|l|}{ Moxifloxacin } \\
\hline $400 \mathrm{mg}$ & $3.0(2.78,3.25)$ & $16.35(14.03,18.68)$ & $\begin{array}{l}4.47(3.58,5.36) \\
p<0.0001\end{array}$ & $\begin{array}{l}2.89(1.82,3.97) \\
p<0.0001\end{array}$ \\
\hline
\end{tabular}

$\mathrm{Cl}$, confidence interval; $C_{\text {max }}$, maximum plasma concentration; $\Delta$, change-from-baseline; $\Delta \Delta$, placebo-corrected change-from-baseline; QTcF, Fridericia-corrected QTC 
Table 4 Summary of treatment-emergent AEs by treatment

\begin{tabular}{|c|c|c|c|c|c|c|c|c|c|c|c|c|}
\hline & \multicolumn{6}{|c|}{ Lucerastat } & \multicolumn{6}{|c|}{ Placebo } \\
\hline & \multicolumn{3}{|c|}{$2000 \mathrm{mg}$} & \multicolumn{3}{|c|}{$4000 \mathrm{mg}$} & \multicolumn{3}{|l|}{ Day 1} & \multicolumn{3}{|l|}{ Day 3} \\
\hline & \multicolumn{3}{|c|}{ Day 1} & \multicolumn{9}{|c|}{ Day 3} \\
\hline & \multicolumn{3}{|l|}{$\mathrm{N}=6$} & \multicolumn{3}{|l|}{$\mathrm{N}=6$} & \multicolumn{3}{|l|}{$\mathrm{N}=2$} & \multicolumn{3}{|l|}{$\mathrm{N}=2$} \\
\hline & nAEs & $\mathbf{n}$ & $\%$ & nAEs & $\mathbf{n}$ & $\%$ & nAEs & $\mathbf{n}$ & $\%$ & nAEs & $\mathbf{n}$ & $\%$ \\
\hline \multicolumn{13}{|l|}{ Part A } \\
\hline \multicolumn{13}{|l|}{ Any PT } \\
\hline Number of subjects with at least one AE & & 1 & 16.7 & & & & & 1 & 50.0 & & & \\
\hline Number of different AEs & 2 & & & & & & 2 & & & & & \\
\hline Total number of AEs & 2 & & & & & & 2 & & & & & \\
\hline \multicolumn{13}{|l|}{ Most common AEs ${ }^{\mathrm{a}}$} \\
\hline Nausea & - & - & - & - & - & - & 1 & 1 & 50.0 & - & - & - \\
\hline Vomiting & - & - & - & - & - & - & 1 & 1 & 50.0 & - & - & - \\
\hline Fatigue & 1 & 1 & 16.7 & - & - & - & - & - & - & - & - & - \\
\hline \multirow[t]{5}{*}{ Nasal congestion } & 1 & 1 & 16.7 & - & - & - & - & - & - & - & - & - \\
\hline & \multicolumn{6}{|c|}{ Lucerastat } & \multicolumn{3}{|c|}{ Moxifloxacin } & \multicolumn{3}{|c|}{ Placebo } \\
\hline & \multicolumn{3}{|c|}{$1000 \mathrm{mg}$} & \multicolumn{3}{|c|}{$4000 \mathrm{mg}$} & \multicolumn{3}{|c|}{$400 \mathrm{mg}$} & & & \\
\hline & \multicolumn{3}{|c|}{$N=36$} & \multicolumn{3}{|c|}{$N=36$} & \multicolumn{3}{|c|}{$\mathrm{N}=35$} & \multicolumn{3}{|c|}{$\mathrm{N}=36$} \\
\hline & nAEs & $\mathrm{n}$ & (\%) & nAEs & $\mathrm{n}$ & (\%) & nAEs & $\mathbf{n}$ & (\%) & nAEs & $\mathbf{n}$ & (\%) \\
\hline \multicolumn{13}{|l|}{ Part B } \\
\hline Any PT & & & & & & & & & & & & \\
\hline Number of subjects with at least one AE & & 12 & 33.3 & & 9 & 25.0 & & 18 & 51.4 & & 9 & 25.0 \\
\hline Number of different AEs & 9 & & & 13 & & & 12 & & & 9 & & \\
\hline Total number of AEs & 16 & & & 17 & & & 30 & & & 12 & & \\
\hline Most common AEs ${ }^{\mathrm{a}}$ & & & & & & & & & & & & \\
\hline Headache & 4 & 4 & 11.1 & 3 & 2 & 5.6 & 4 & 4 & 11.4 & 4 & 4 & 11.1 \\
\hline Dizziness & 2 & 2 & 5.6 & 2 & 2 & 5.6 & 4 & 4 & 11.4 & - & - & - \\
\hline Nausea & - & - & - & - & - & - & 6 & 6 & 17.1 & - & - & - \\
\hline Medical device site reaction & 3 & 3 & 8.3 & - & - & - & 1 & 1 & 2.9 & 1 & 1 & 2.8 \\
\hline Electrocardiogram QT prolonged & - & - & - & 1 & 1 & 2.8 & 8 & 3 & 8.6 & - & - & - \\
\hline Catheter site pain & - & - & - & 2 & 2 & 5.6 & 1 & 1 & 2.9 & - & - & - \\
\hline Catheter site related reaction & 2 & 2 & 5.6 & 1 & 1 & 2.8 & - & - & - & - & - & - \\
\hline
\end{tabular}

a Occurring with a frequency $\geq 5 \%$ with any treatment

$\%$, percentage of subjects based on $\mathrm{N} ; \mathrm{AE}$, adverse event; $\mathrm{N}$, number of subjects in the population; $\mathrm{n}$, number of subjects with available data; $\mathrm{PT}$, preferred term

healthy subjects (as opposed to individuals at increased risk of arrhythmias) [18]. The intention of the TQT study in healthy subjects is to evaluate whether the drug causes clinically concerning QTc prolongation, not to directly assess the pro-arrhythmic potential in a clinical setting. Susceptible patients may develop pronounced QTc prolongation and torsades de pointes at drug concentrations that can be safely achieved in healthy subjects. To the best of our knowledge, examples of a drug causing QTc prolongation in patients only, but not in healthy subjects, do not exist, provided the drug has been evaluated in healthy subjects at sufficiently high exposure.
Both male and female subjects were included since females have a longer QTc interval and an increased risk of pro-arrhythmias caused by drug-induced delayed cardiac repolarization [25]. In addition, current guidance is encouraging, although not mandating, to include both sexes in a TQT study [19]. A crossover design with 4 periods separated by a washout period was chosen to allow intra-subject comparison of the 4 study treatments, thus, reducing variability and, therefore, decreasing the number of subjects needed for the study $[26,27]$. Since moxifloxacin was given open-label, $34 \times 4$ Williams squares were used for randomization to retain the study 
blind and to ensure that first-order carry-over effects were balanced.

Regulatory guidance recommends that, if not precluded by considerations of safety or tolerability, a drug should be tested in TQT studies at substantial multiples of the anticipated maximum therapeutic exposure [18]. Since clinical experience with doses higher than the anticipated therapeutic dose of $1000 \mathrm{mg}$ lucerastat twice daily was lacking, Part A investigated the safety, tolerability, and PK of 2000 and $4000 \mathrm{mg}$ lucerastat. Based on results from Part $\mathrm{A}$, the supratherapeutic dose of $4000 \mathrm{mg}$ lucerastat was selected for Part B. This dose is regarded as a substantial multiple considering the following observations. Lucerastat is largely eliminated unchanged via renal excretion [15]. Therefore, it is not expected that hepatic impairment will affect the PK of lucerastat. In subjects with renal impairment, the exposure to lucerastat increased depending on the severity of their disease. Whereas the PK characteristics of lucerastat in subjects with mild renal impairment and healthy subjects were similar, the $\mathrm{AUC}_{0-\infty}$ of lucerastat was 1.6- and 3.2-fold higher in subjects with moderate and severe renal impairment, respectively [28]. Therefore, dose reductions must be applied in subjects with moderate or severe renal impairment leading to similar exposure to lucerastat as in subjects with normal kidney function. Lucerastat is not prone to drug-drug-interactions and no such interaction is expected to increase exposure to lucerastat more than 1.2-fold. Results from a clinical drug-drug-interaction study with the organic cation transporter 2 inhibitor cimetidine in healthy male subjects demonstrated that cimetidine had only a weak effect on the exposure to lucerastat, i.e., led to an increase of geometric mean $\mathrm{C}_{\max }$ and $\mathrm{AUC}$ by about 4 and $23 \%$, respectively, at cimetidine steady state [29]. Food intake did not affect the total systemic exposure to lucerastat in a clinically relevant manner [15]. Taken together, there are no intrinsic or extrinsic factors expected to increase exposure to lucerastat combined to more than approximately 1.5 -fold, provided the dose reductions for subjects with renal impairment are applied.

The use of single-dose administration to investigate the QTc effects of lucerastat is in line with current guidance that indicated that for drugs with a short $t_{1 / 2}$ and no metabolites a single dose study might be sufficient [18], considering that lucerastat has indeed a short $t_{1 / 2}$, does not accumulate, and is not metabolized to any great extent $[15,28]$.

Employing concentration-QTc analysis as primary analysis is in line with a recent revision of the applicable regulatory guidance [19] and the recently published white paper outlining the statistical principles [20]. Hence, it is considered appropriate to determine the effect of lucerastat at therapeutic and supratherapeutic doses on the QTc interval. Placebo is required in concentrationQTc analysis to correct for spontaneous diurnal variation, to control for potential bias introduced by study procedures, and to increase the power to exclude modest QTc effects in small-sized studies. The use of moxifloxacin as a positive control to detect small increases in QTc from baseline allowed appropriate assessment of assay sensitivity. The dose of $400 \mathrm{mg}$ is the therapeutic dose and commonly used in TQT studies since it has been reproducibly shown to prolong the QTc interval [30, 31].

The moxifloxacin QTc response observed in this study clearly demonstrated assay sensitivity. The linear model seemed to slightly overestimate the QTc effect at high moxifloxacin plasma concentrations and a statistically significant treatment effect-specific intercept, i.e., at concentration zero, indicated that the model specification was not optimal. However, since assay sensitivity was also demonstrated in the by-time point analysis, with the lower bound of the $90 \% \mathrm{CI}$ of the largest mean $\Delta \Delta \mathrm{QTCF}$ above $5 \mathrm{~ms}$, no further efforts were made to improve the concentration-QTc model for moxifloxacin by fitting additional nonlinear models. The observed mean $\mathrm{C}_{\max }$ of moxifloxacin occurred at $2 \mathrm{~h}$ post-dose. A difference of $30 \mathrm{~min}$ was observed between the moxifloxacin mean $\mathrm{C}_{\max }$ and the maximum LS mean $\Delta \Delta \mathrm{QTCF}$ of $13.9 \mathrm{~ms}$ at $1.5 \mathrm{~h}$ post-dose. However, the effect of moxifloxacin on $\Delta \Delta$ QTcF is well characterized [31] and the small difference below $1 \mathrm{~h}$ did not warrant further exploration. Overall, the effect of moxifloxacin observed in this study was in concordance with previously described effects [30, 31].

Based on concentration-QTc analysis, a QTcF effect above $10 \mathrm{~ms}$ could be excluded up to lucerastat plasma concentrations of approximately $34 \mu \mathrm{g} / \mathrm{mL}$. For both lucerastat doses, $\mathrm{C}_{\max }$ and peak LS mean $\Delta \Delta \mathrm{QTcF}$ occurred at $2.5 \mathrm{~h}$ post-dose demonstrating the lack of hysteresis. This was confirmed by graphical displays (data not shown) The effect of both doses of lucerastat on $\Delta \Delta \mathrm{QTcF}$ was negligible and the largest mean effect, i.e., $2.6 \mathrm{~ms}$, occurred after dosing with $4000 \mathrm{mg}$. The reduction of $\Delta \mathrm{QTcF}$ observed with all study treatments at 6 and $8 \mathrm{~h}$ post-dose might be explained by the QTc shortening effect of a standardized meal, i.e., in this study the administration of lunch at $4 \mathrm{~h}$ post-dose, which may be correlated to the postprandial increase in cardiac output and the effect of $C$ peptide and glucose on cardiac repolarization as described previously [32, 33].

At the geometric mean $\mathrm{C}_{\max }$ of $24.3 \mu \mathrm{g} / \mathrm{mL}$ after administration of $4000 \mathrm{mg}$ lucerastat the upper bound of the $90 \% \mathrm{CI}$ of the predicted $\Delta \Delta \mathrm{QTcF}$ was $3.05 \mathrm{~ms}$. Considering this and since the exposure to lucerastat increases approximately dose-proportionally it is not 
expected that in a clinical worst-case scenario lucerastat plasma concentrations might be reached leading to a QTcF effect of clinical concern, provided the dose reduction scheme for patients with renal function impairment is followed.

Lucerastat at single oral doses up to $4000 \mathrm{mg}$ was safe and well tolerated in both parts of the study. Overall, the safety profile observed in this study was in accordance with previous clinical experience.

In this TQT study, the anticipated therapeutic dose of $1000 \mathrm{mg}$ and a supratherapeutic dose of $4000 \mathrm{mg}$ lucerastat had no clinically relevant effect on the QTcF interval. This will be an important factor in the overall benefit-risk assessment of lucerastat in the potential treatment of FD since many Fabry patients suffer from cardiac morbidities including arrythmias.

\section{Conclusions}

These results constitute a negative TQT study as described in the applicable regulatory guidance, demonstrating that lucerastat up to a single dose of $4000 \mathrm{mg}$ does not have any clinically relevant liability to prolong the QT interval or any clinically relevant effect on other ECG parameters. In addition, lucerastat was safe and well tolerated even at the supratherapeutic dose, which represents a fourfold higher dose than the currently investigated therapeutic dose, covering a clinical worstcase scenario. The favorable safety profile of lucerastat observed in previous studies was confirmed.

\begin{abstract}
Acknowledgements
The authors would like to thank the subjects for participating in this study and the contractors for their work; namely, Klaske van Kammen and the study team at QPS Netherlands B.V. (Groningen, The Netherlands) for project management and the clinical conduct of the study; Mariya Antonova at Aixial s.r.o. (Brno, Czech Republic) for the statistical analysis of clinical data excluding Holter ECG analysis; and Lena Borkowski and Kerstin Steigerwald at ACC GmbH Analytical Clinical Concepts (Leidersbach, Germany) for the bioanalysis of moxifloxacin. In addition, the authors wish to thank the members of Idorsia Pharmaceuticals Ltd (Allschwil, Switzerland) for the work on the study; namely, Racheal Rowles (project management), Denis Boutin (data management), Antonella Santilli (clinical data monitoring), Antonio Crucitti (drug safety), Susanne Globig and Giancarlo Sabattini (lucerastat bioanalytical work), and Magda Fontes (medical writing assistance). Finally, MSM would like to thank Andrea Henrich for all discussions and support with regards to modeling and simulation.
\end{abstract}

\section{Authors' contributions}

MSM, PNS, BD, HX, and JD designed, evaluated, and reported the study; CV-P was the principal investigator of the study and critically reviewed the data. MSM drafted the manuscript. All authors critically reviewed the draft manuscript. All authors read and approved the final manuscript.

\section{Funding}

This study was funded by Idorsia Pharmaceuticals Ltd.

\section{Availability of data and materials}

The datasets supporting the conclusions of this article are included within the clinical study report from the study presented in the manuscript. The key data supporting the findings of this study are available within the article.

\section{Ethics approval and consent to participate}

The study was approved by the local Ethics Committee (Medisch Ethische Toetsings Commissie, Assen, The Netherlands). Written informed consent was obtained from each subject prior to enrolment in the study, which was conducted at QPS Netherlands B.V. (Groningen, The Netherlands), in accordance with the revised Declaration of Helsinki principles, International Council for Harmonization Good Clinical Practice guidelines, and applicable laws and regulations.

\section{Consent for publication}

Not applicable.

\section{Competing interests}

Idorsia Pharmaceuticals Ltd (Allschwil, Switzerland) sponsored this study. All authors had support from Idorsia for the submitted work; MSM, PNS, and JD are full-time employees of Idorsia and owners of stock units and/or restricted stock units from Idorsia. CV-P is a full-time employee of the clinical research organization QPS Netherlands B.V. (Groningen, The Netherlands) contracted to conduct the study; no other competing interests have been raised. $\mathrm{HX}$ is a full-time employee of the ECG service provider eResearch Technology Inc. $\left(E R T^{\circledR}\right.$, Rochester, NY, USA) contracted for the evaluation of cardiac safety and statistical analysis of Holter ECG data; BD is a consultant for ERT ${ }^{\circledR}$ and owns stock and is eligible for stock options in the company. No other competing interests have been raised.

\section{Author details}

${ }^{1}$ Department of Clinical Pharmacology, Idorsia Pharmaceuticals Ltd, Hegenheimermattweg 91, 4123 Allschwil, Switzerland. ${ }^{2}$ QPS Netherlands B.V., Groningen, The Netherlands. ${ }^{3}$ eResearch Technology Inc, ERT, Rochester, NY, USA.

Received: 14 June 2020 Accepted: 13 October 2020

Published online: 27 October 2020

\section{References}

1. Germain DP. Fabry disease. Orphanet J Rare Dis. 2010;5:30. https://doi. org/10.1186/1750-1172-5-30.

2. Schiffmann R, Ries M. Fabry disease: a disorder of childhood onset. Pediatr Neurol. 2016;64:10-20. https://doi.org/10.1016/j.pediatrneu rol.2016.07.001.

3. Miller JJ, Kanack AJ, Dahms NM. Progress in the understanding and treatment of Fabry disease. Biochim Biophys Act Gen Subj. 2020;1864(1):129437. https://doi.org/10.1016/j.bbagen.2019.129437.

4. Felis A, Whitlow M, Kraus A, Warnock DG, Wallace E. Current and investigational therapeutics for Fabry disease. Kidney Int Rep. 2020;5(4):407-13. https://doi.org/10.1016/j.ekir.2019.11.013.

5. Feriozzi S, Hughes DA. New drugs for the treatment of Anderson-Fabry disease. J Nephrol. 2020. https://doi.org/10.1007/s40620-020-00721-4.

6. Pisani A, Visciano B, Roux GD, Sabbatini M, Porto C, Parenti G, Imbriaco M. Enzyme replacement therapy in patients with Fabry disease: state of the art and review of the literature. Mol Genet Metab. 2012;107(3):267-75. https://doi.org/10.1016/j.ymgme.2012.08.003.

7. Hughes DA, Nicholls K, Shankar SP, et al. Oral pharmacological chaperone migalastat compared with enzyme replacement therapy in Fabry disease: 18-month results from the randomised phase III ATTRACT study. J Med Genet. 2017;54(4):288-96.

8. McCafferty EH, Scott LJ. Migalastat: a review in Fabry disease. Drugs. 2019;79:543-54. https://doi.org/10.1007/s40265-019-01090-4.

9. Lenders M, Stypmann J, Duning T, Schmitz B, Brand SM, Brand E. Serummediated inhibition of enzyme replacement therapy in Fabry disease. J Am Soc Nephrol. 2016;27(1):256-64. https://doi.org/10.1681/ASN.20141 21226.

10. Linthorst GE, Hollak CEM, Donker-Koopman WE, Strijland A, Aerts JMFG. Enzyme therapy for Fabry disease: neutralizing antibodies toward agalsidase alpha and beta. Kidney Int. 2004;66(4):1589-95. https://doi.org/10.1 111/j.1523-1755.2004.00924.x.

11. European Medicines Agency. Galafold ${ }^{\circledR}$ (migalastat) 123 mg hard capsules: summary of product characteristics. https://www.ema.europa.eu/ 
docs/en_GB/document_library/EPAR_-_Product_Information/human /004059/WC500208434.pdf. Accessed 24 April 2020.

12. United States Food and Drug Administration. Galafold ${ }^{\circledR}$ (migalastat) capsules for oral use: prescribing information. https://www.accessdata.fda. gov/drugsatfda_docs/label/2018/208623lbl.pdf. Accessed 24 April 2020.

13. Welford RWD, Mühlemann A, Garzotti M, et al. Glucosylceramide synthase inhibition with lucerastat lowers globotriaosylceramide and lysosome staining in cultured fibroblasts from Fabry patients with different mutation types. Hum Mol Genet. 2018;27(19):3392-403. https://doi. org/10.1093/hmg/ddy248.

14. Guérard N, Oder D, Nordbeck P, et al. Lucerastat, an iminosugar for substrate reduction therapy: tolerability, pharmacodynamics, and pharmacokinetics in patients with Fabry disease on enzyme replacement. Clin Pharmacol Ther. 2018;103(4):703-11. https://doi.org/10.1002/cpt.790.

15. Guérard N, Morand O, Dingemanse J. Lucerastat, an iminosugar with potential as substrate reduction therapy for glycolipid storage disorders: safety, tolerability, and pharmacokinetics in healthy subjects. Orphanet $\rfloor$ Rare Dis. 2017:12:9. https://doi.org/10.1186/s13023-017-0565-9.

16. Acharya D, Robertson P, Kay NG, et al. Arrhythmias in Fabry cardiomyopathy. Clin Cardiol. 2012;35(12):738-40. https://doi.org/10.1002/clc.22047.

17. Schiffmann R, Warnock DG, Banikazemi M, et al. Fabry disease: progression of nephropathy, and prevalence of cardiac and cerebrovascular events before enzyme replacement therapy. Nephrol Dial Transpl. 2009;24(7):2102-11. https://doi.org/10.1093/ndt/gfp031.

18. International Conference on Harmonisation of Technical Requirements for Registration of Pharmaceuticals for Human Use. E14 Guideline: the clinical evaluation of QT/QTc interval prolongation and proarrhythmic potential for non-antiarrhythmic drugs. Step 4. May 12, 2005. https:// database.ich.org/sites/default/files/E14_Guideline.pdf. Accessed 24 May 2020

19. International Council for Harmonisation of Technical Requirements for Pharmaceuticals for Human Use. E14 Guideline: The clinical evaluation of QT/QTc interval prolongation and proarrhythmic potential for nonantiarrhythmic drugs. Questions \& Answers (R3). December 10, 2015. https://database.ich.org/sites/default/files/E14_Q\%26As_R3_Q\%26As. pdf. Accessed 24 May 2020.

20. Garnett C, Bonate PL, Dang Q, et al. Scientific white paper on concentration-QTc modeling. J Pharmacokinet Pharmacodyn. 2018;45(3):383-97. https://doi.org/10.1007/s10928-017-9558-5.

21. Darpo B, Benson C, Dota C, et al. Results from the IQ-CSRC prospective study support replacement of the thorough QT study by QT assessment in the early clinical phase. Clin Pharmacol Ther. 2015;97(4):326-35. https ://doi.org/10.1002/cpt.60.

22. Ferber G, Zhou M, Darpo B. Detection of QTc effects in small studies-implications for replacing the thorough QT study. Ann Noninvasive Electrocardiol. 2015;20(4):368-77. https://doi.org/10.1111/anec.12227.
23. Williams EJ. Experimental designs balanced for the estimation of residual effects of treatments. Austr J Sci Res. 1949;2(2):149-68. https://doi. org/10.1071/CH9490149.

24. Darpo B, Fossa AA, Couderc JP, et al. Improving the precision of QT measurements. Cardiol J. 2011;18(4):401-10.

25. Makkar RR, Fromm BS, Steinman RT, Meissner MD, Lehmann MH. Female gender as a risk factor for torsades de pointes associated with cardiovascular drugs. JAMA. 1993;270(21):2590-7.

26. Darpo B. The thorough QT/QTc study 4 years after the implementation of the ICH E14 guidance. Br J Pharmacol. 2010;159(1):49-57. https://doi.org/ 10.1111/j.1476-5381.2009.00487.x.

27. Zhang J, Machado SG. Statistical issues including design and sample size calculation in thorough QT/QTc studies. J Biopharm Stat. 2008;18(3):45167. https://doi.org/10.1080/10543400802020938.

28. Guérard N, Zwingelstein C, Dingemanse J. Lucerastat, an iminosugar for substrate reduction therapy: pharmacokinetics, tolerability, and safety in subjects with mild, moderate, and severe renal function impairment. J Clin Pharmacol. 2017;57(11):1425-31. https://doi.org/10.1002/jcph.944.

29. Boof ML, Halabi A, Ufer M, Dingemanse J. Impact of the organic cation transporter 2 inhibitor cimetidine on the single-dose pharmacokinetics of the glucosylceramide synthase inhibitor lucerastat in healthy subjects. Eur J Clin Pharmacol. 2020;76(3):431-7. https://doi.org/10.1007/s0022 8-019-02808-9.

30. Yan LK, Zhang J, Ng MJ, Dang Q. Statistical characteristics of moxifloxacininduced QTc effect. J Biopharm Stat. 2010;20(3):497-507. https://doi. org/10.1080/10543400903581945

31. Florian JA, Tornøe CW, Brundage R, Parekh A, Garnett CE. Population pharmacokinetic and concentration-QTC models for moxifloxacin: pooled analysis of 20 thorough QT studies. J Clin Pharmacol. 2011;51(8):1152-62. https://doi.org/10.1177/0091270010381498.

32. Taubel J, Ferber G, Lorch U, Batchvarov V, Savelieva I, Camm AJ. Thorough QT study of the effect of oral moxifloxacin on QTc interval in the fed and fasted state in healthy Japanese and Caucasian subjects. Br J Clin Pharmacol. 2013;77(1):170-9. https://doi.org/10.1111/bcp.12168.

33. Täubel J, Ferber G, Fernandes S, Lorch U, Sust M, Camm AJ. The effects of a meal on QTc to demonstrate ECG assay sensitivity in phase I studies. J Bioequiv Bioavailab. 2016;8(6):272-3.

\section{Publisher's Note}

Springer Nature remains neutral with regard to jurisdictional claims in published maps and institutional affiliations.
Ready to submit your research? Choose BMC and benefit from:

- fast, convenient online submission

- thorough peer review by experienced researchers in your field

- rapid publication on acceptance

- support for research data, including large and complex data types

- gold Open Access which fosters wider collaboration and increased citations

- maximum visibility for your research: over 100M website views per year

At BMC, research is always in progress.

Learn more biomedcentral.com/submissions 